\title{
Bakhtin e/com Pêcheux? Pressupostos de trabalho em linguística aplicada ${ }^{1}$
}

Maria Marta Furlanetto*

\section{Resumo}

Este trabalho trata de categorias aparentemente contraditórias, visualizadas em perspectivas teóricas diferentes - a de Bakhtin e seu grupo (teoria dialógica) e a análise de discurso, de filiação francesa -, mas que merecem estudo paralelo considerando seu encontro histórico na Europa, pela migração de um texto do pesquisador russo. Dada, de um lado, a afirmação de impossibilidade de conciliar as duas teorias e, de outro, os estudos que refletem sobre as razões de as duas serem usadas para o estudo de determinados temas e campos realizando aproximações, a memória dos (des)encontros pode explicar afinidades e diferenças, além de mostrar que ressonâncias teóricas podem instalar-se nesses campos de estudo. O trabalho objetiva formular argumentos e fornecer razões práticas para o uso de certas categorias, contemporaneamente, em áreas de prática de linguagem, tal como a linguística aplicada. Assim, noções como discurso, sujeito, ideologia, memória, interdiscurso, heterogeneidade e gênero são consideradas nesta reflexão.

Palavras-chave: Análise de discurso. Dialogismo. Linguística aplicada.

\section{Introdução}

Dada, de um lado, a afirmação de impossibilidade de conciliar duas teorias como o dialogismo bakhtiniano (ou do que se tem chamado Círculo de Bakhtin) e a análise de discurso francesa - especialmente a originada em Pêcheux (cf. POSSENTI, 2010; SÉRIOT, 2011) ${ }^{2}$, e, de outro, os estudos que refletem sobre as razões de as duas, criticamente ou não, serem usadas para o estudo de determinados temas e campos realizando aproximações (NARZETTI, 2012), a memória dos (des)encontros pode explicar afinidades e distanciamentos. Quero dizer, mais especificamente, que é possível conjeturar que ressonâncias teóricas possam instalar-se em campos inicialmente muito fechados, que manifestam receio de perda de identidade uma vez instaurados seus alicerces e categorias de funcionamento. Isso, contudo, sucede com as próprias noções teóricas, que se deslocam e se redesenham paulatina-

\footnotetext{
Docente do Programa de Pós-Graduação em Ciências da Linguagem da Universidade do Sul de Santa Catarina. E-mail: mmartafurlanetto@gmail.com
}

Data de submissão: maio 2018 - Data de aceite: jun. 2018 http://dx.doi.org/10.5335/rdes.v14i2.8190 
mente no interior de uma mesma teoria. Dizia Michel Plon (2003, p. 2), em sua conferência no $1^{\circ}$ Seminário de Estudos em Análise do Discurso (Sead): "Retificação, Michel [Pêcheux] gostava desse termo, que não tem nada de secundário", e que ele exercitou em seu trabalho teórico: transformações, revisões, questionamentos, abandono.

Bakhtin recomendou, relativamente à alteridade (outridade, heterogeneidade, heteroglossia, polifonia), que não nos cercássemos apenas daqueles de nossa comunidade, sobretudo na vida intelectual, em busca de segurança e partilhamento; os outros (a exterioridade) podem trazer olhares e aproximações pertinentes para a articulação de nossos projetos - nada diferente do que ocorreu na época em que Pêcheux enfeixou orientações divergentes para produzir seu objeto de estudo - o discurso em sua peculiaridade. Quanto a isso, Emerson (2003) destaca: "Bakhtin nos recomenda não nos voltarmos para um lugar onde ninguém se orienta em nossa direção, pois não existem meios de vida nesse lugar" (2003, p. 270). Ou seja, um agrupamento intelectual que ostente perspectivas de segurança e identidade pode, ao contrário do previsível, ser empobrecedor. E Possenti (2010), nessa linha, se ressente de não haver suficientemente debates abertos sobre temas pertinentes que poderiam marcar a pertença ou não entre teorias, relações, eventuais aproximações, extensões e mesmo debates sobre conceitos e categorias no contexto próprio de cada teoria - como ele tem feito continuamente, aliás, em seus textos.

Com esse espírito, entendendo que certas razões práticas podem levar a justificar o uso articulado de categorias ou perspectivas em áreas específicas, no caso o amplo campo da linguística aplicada, estabeleço como objetivos deste trabalho os seguintes, pondo em movimento algumas noções selecionadas - sujeito, ideologia, memória, interdiscurso, polifonia, heterogeneidade e gênero:

a) investir em categorias que, em dois circuitos teóricos (dialogismo e análise de discurso), carecem de estudo paralelo em virtude de seu encontro histórico na Europa;

b) estabelecer afinidades e distanciamentos, considerando deslocamentos no tempo, tanto das teorias quanto de seu refinamento;

c) justificar o uso de categorias nos dois campos para direcionar práticas de linguagem com a cobertura da linguística aplicada.

Não se trata, certamente, de instituir uma interface ou um novo quadro conceptual (embora isso não seja impensável), nem de combinar aleatoriamente as duas perspectivas sem qualquer compatibilização. A questão é exatamente essa, ainda que se queira, fundamentalmente, pensar em uma prática em que, para estudantes iniciantes, o principal seja que aprendam atitudes e ações relativamente ao aprendizado ou ao desenvolvimento de línguas, por exemplo. Também é relevante ter ciência de que, 
se uma teoria é inicialmente a base para o estabelecimento de uma metodologia de ensino, que noção ou categoria sofrerá compatibilização quando tratada nos moldes de outra teoria, e por quê? E se optarmos por um terceiro caminho?

\section{$\mathrm{AD} / \mathrm{ADD}$}

Se desejarmos estabelecer uma teoria que tenha, em seu próprio nome, um objeto denominado discurso (como em análise de discurso $[\mathrm{AD}] \mathrm{e}$, ainda, análise dialógica do discurso [ADD]), a questão inicial é compreender discurso. No caso da $\mathrm{AD}$, assumo que discurso não equivale a texto, aliás, distancia-se teoricamente de texto, em que se reconhece materialidade, organização estrutural, temática, estilo - além da materialidade de gênero, categoria que a $\mathrm{AD}$ secundariza. Isso não significaria, entretanto, que em $\mathrm{AD}$ não se precise da textualidade. Apenas - até o momento - se prescinde de gênero como conceito associado (por quê?). Abordo isso mais à frente. Adiante-se apenas que, na teoria dialógica de Bakhtin, um gênero está sempre associado a uma esfera social - um campo funcional com determinações e produções ideológicas no interior da sociedade em que gêneros específicos se formam, se desenvolvem e se modificam. Da mesma forma, em AD, a inscrição em um campo institucional é crucial, embora a caracterização "interacional" ou "sociointeracional", comum para a linha bakhtiniana, não pareça suficiente.
Discurso como objeto da $\mathrm{AD}$ redunda em efeitos de sentido entre sujeitos. De imediato, porque se assume que sentidos se formam, são instáveis, dependem de uma memória; essa historicidade leva a que sentidos que parecem evidentes sejam ilusórios. A noção de literal não passa de uma referência, mas ela faz "sentido" heuristicamente falando, como ponto de vista.

Os sentidos nascem primariamente da memória, ou das memórias: enunciados em geral, imagens, lembranças que ressurgem, aspectos da coletividade, e elementos que se presentificam nos arquivos de todo tipo que consultamos. Sentidos são efeitos que surgem e ressurgem em diversas histórias, tempos, circunstâncias, sujeitos participantes - participantes necessários, ainda que virtuais. Nessa direção, também elementos de interações, como estabelecido francamente por Bakhtin: a palavra (enunciado) é ponte entre interlocutores (intersubjetividade). Mas sentidos são dados, de imediato, como efeitos que surgem pelo fato de haver filiações discursivas, e estas seriam, antes de tudo, o fundo de percepção "instintiva" praticamente independente da consciência: interdiscurso.

Dada a predominância dessa perspectiva quando a formação discursiva era um conceito não instável e duvidoso na teoria, afirmou-se, não poucas vezes, que tudo o que era produzido pelo "sujeito" vinha de um fundo basicamente inconsciente, tal qual a memória metálica de 
um robô. Contudo, efeitos não podem surgir apenas do interdiscurso - que por sua vez não pode ter sentidos (mas potencialidade para), mas eu diria, especificamente, significado ou significação, para diferenciar o percurso para o intradiscurso, até se tornar efeito entre interlocutores, ou sujeitos. Esse contraste é realizado na formulação de Bakhtin (ou de Voloshinov, como admitem alguns autores), em Marxismo e filosofia da linguagem (MFL), como se vê adiante.

É possível ratificar essa posição com a assunção de Sobral a respeito de uma tese de Bakhtin, de que "a língua não traz intrinsecamente sentidos, mas possibilidades reconhecíveis de produção de sentidos que dependem, simplifiquemos, de quem diz o que a quem onde como e com que projeto enunciativo" (2010, p. 55). Outra forma de ratificação encontra-se em Maingueneau, em uma entrevista publicada na revista Linguasagem: "O sentido é uma estimulação para que cada um possa construir o sentido" (2009, sem paginação). Mais especificamente, nos termos de minha explicação, ele está dizendo que podemos ter, textualmente, significação, mas não sentido (efeito).

Ao focalizar a memória em um projeto de pesquisa em 1983, Pêcheux (1990b, p. 286, grifos do autor) fala no estatuto social da memória, que compreenderia um conjunto preexistente e exterior ao organismo "constituído por séries de tecidos de índices legíveis, constituindo um corpo sócio-histórico [sic] de traços".
São esses traços coletivos (interdiscurso?) que levam Pêcheux a remeter a Bakhtin, nesse momento - embora ele não cite diretamente Bakhtin, mas Todorov, que apresenta a obra $M$. Bakhtine, le principe dialogique, de 1981. Pêcheux também escreveu, no último período de seu trabalho, que "[...] a memória discursiva seria aquilo que, face a um texto que surge como acontecimento a ser lido, vem restabelecer os 'implícitos' [...] de que sua leitura necessita: a condição do legível em relação ao próprio legível" (PÊCHEUX, 1999, p. 52). Implícitos não seriam formas reais em espera, mas se formariam num processo de regularização (estabilidade) do que é repetido, o que incluiria a formação de estereótipos - materialidades naturalizadas, digamos, disponíveis e usadas. A regularização, contudo, está sujeita a colapso (incluindo o jogo variável da metáfora).

Tendo em vista essa remissão a traços memoriais de corpos discursivos, não é de estranhar que se tomasse de empréstimo, na linha bakhtiniana, para a análise linguístico-discursiva, a noção de interdiscurso, dotando-a de uma memória mais rica. Com a suavização de conceitos, Pêcheux abria espaço para continuar seu próprio projeto e, concomitantemente, impedia discrepâncias muito marcadas com outras teorias do discurso. Beth Brait, ao caracterizar o dialogismo bakhtiniano, destaca duas faces: "[...] o dialogismo diz respeito ao permanente diálogo, nem sempre 
simétrico e harmonioso, existente entre os diferentes discursos que configuram uma comunidade, uma cultura, uma sociedade" (1997, p. 98); e também "[...] diz respeito às relações que se estabelecem entre o eu e o outro nos processos discursivos instaurados historicamente pelos sujeitos, que, por sua vez, instauram-se e são instaurados por esses discursos" (1997, p. 98). Quanto ao primeiro ponto, é em função dele que o dialogismo é interpretado como aquilo que instaura "a constitutiva natureza interdiscursiva da linguagem" (1997, p. 98, grifo meu). Brait defende, aliás, que está evidenciado em MFL que a possibilidade de estudar o discurso (enunciado, para considerar o alerta de Patrick Sériot) se faz vendo-o como instância significativa, entrelaçamentos discursivos (interdiscurso) veiculados socialmente nas interações subjetivas (cf. 1997, p. 99).

\section{Sujeito de/sujeito a}

O sujeito, que se apresenta igualmente como elemento em construção, tem, na verdade, duas formas na $\mathrm{AD}$ (porque é preciso tomá-lo também pragmaticamente).

Sujeito 1 - Quando dizemos que o sujeito (que fala, vive, pensa, age) tem a ilusão de que suas palavras se originam nele mesmo, estamos tomando-o pelo que ele tem de pessoalidade, de alguém que ocupa um lugar social e aí se pronuncia. Esse sujeito pragmático é também um locutor, ou interlocutor, ou enunciador de uma enunciação (e aí também está num limiar enunciativo). Assim como o linguístico - ou outra semiose - é a base material do texto, o sujeito 1 é seu suporte físico-biológico como ser social. Aliás, o corpo passou a ser valorizado como suporte até mesmo de inscrição de linguagem (letras, gestos, tatuagens em geral, pintura, piercing, manipulação física) -, que, mesmo sem endereçamento imediato, sendo flutuante, produz efeitos sociais: as marcas podem ser "lidas", causam impressão, como se se tratasse de uma exposição.

Nesse "formato", seria conveniente chamar esse sujeito de efeito-sujeito, como Pêcheux, aliás, usou em certas passagens de Semântica e discurso e com Fuchs - de A propósito da análise automática do discurso: atualização e perspectivas (1975), para indicar precisamente que haveria aí um processo ilusório, como efeito ideológico. Veja-se este exemplo: “[...] o procedimento AAD constitui o esboço de uma análise não-subjetiva dos efeitos de sentido que atravessa[m] a ilusão do efeito-sujeito (produção/leitura) [...]" (PÊCHEUX; FUCHS, 1990[1975], p. 170). Ou, ainda, o que é apenas uma variante, ego-sujeito ou sujeito-ego - veja-se o ponto em que ele fala de "sujeito-ego da 'forma-sujeito' ideológica, identificada com a evidência de um sentido"3 (PÊCHEUX, 1988[1975], p. 300). Essa distinção técnica, entretanto, não é sistematicamente usada; Pêcheux apelava para ela substancialmente quando tratava de perto a psicanálise e para fugir da ambiguidade em pontos sensíveis do desenvolvimento teórico. 
Ao se reconhecer a heterogeneidade enunciativa tal como Authier-Revuz (1984) a traz, tendo um dos pilares o reconhecimento da alteridade, a chamada conotação autonímica, com suas formas marcadas, presume um sujeito-locutor que inscreve palavras "alheias" (dos outros, de outros lugares) e simultaneamente dá atenção a essas palavras (com aspas, itálico, etc., acrescentando eventualmente glosas), voltando-se sobre elas e trazendo algum tipo de comentário. Aqui não se manifesta meramente $o$ interdiscurso; reconhece-se o esquecimento $\mathrm{n}^{\mathrm{o}} 2$, da ordem da enunciação - embora Pêcheux defenda que o funcionamento inconsciente se sobreponha à produção.

Sujeito 2 - Quando dizemos: "Aqui identifico a posição-sujeito $X$ ” - ou seja, falar social caracterizado por uma posição ideológica - a dominante, a conservadora, a neoliberal, a de esquerda, a subversiva... associada a filiações, estamos tocando na noção estrita de sujeito, caracterizando uma - rigorosamente falando - não subjetividade (sujeito dividido), sem que perca seu caráter de elemento social (ou mesmo de classe), portanto afetado pela exterioridade.

Nos dois casos, entretanto, deve-se pensar que subjetividade também é efeito, além de sujeito pragmático, sujeito marcado pelo inconsciente, que o divide, e pela memória, que lhe dá recursos para produzir e interpretar, construindo-se junto com o que faz e o que diz, projetando-se como efeito de uma posição-sujeito, a cada projeto enunciativo. Um não sobrevive sem o outro. Um autor que produz textos é um elemento à margem, no sentido de estar em um limiar: para um antes, como elemento pragmático que tem sua complexa vida social; para um depois, aberto à interpretação na medida em que se manifestou sobre algo do mundo e assumiu um lugar discursivo específico. As duas figuras, no entanto, atuam em conjunto: uma pode ficar obnubilada pela outra, nas perspectivas teóricas, mas ela sempre produz sua própria sombra, ou talvez se possa dizer suas "cicatrizes", mais ou menos perenes. ${ }^{4}$ Apesar de, em 1968, Barthes (2004) ter decretado a "morte do autor" - aliás, num sentido bem específico, embora radical na ocasião -, ele mesmo reconheceu que a autoria, em uma sociedade como a nossa, está bem defendida, inclusive pelos sujeitos pragmáticos que são os escritores.

Não é incomum, em $\mathrm{AD}$, lidarmos descuidadamente com essas noções, por exemplo, afirmando e inscrevendo os "discursos" (manifestações de linguagem) dos professores, dos juízes, dos jornalistas, etc., quando se sabe que discurso (como efeito de sentido) é objeto a ser buscado por análise, não dado, e sem o que nada saberemos dos efeitos de sentido possíveis. Retomo o que destaquei em trabalho anterior (FURLANETTO, 2016, p. 105): considerando temporalidade, desenvolvimentos e mudanças teóricas, é preciso evitar algo que tem ocorrido no campo da $\mathrm{AD}$ : "uma convivência naturalizada de concepções que destoam ou são 
mesmo conflitantes". Já na atualização (em 1975) da Análise Automática do Discurso (AAD-69), Pêcheux e Fuchs (1990, p. 178-179) tratam de precisar que "discurso" não é "fala", nem "um suplemento social do enunciado". Em suma, o elemento discursivo é perspectivado "como um processo social cuja especificidade reside no tipo de materialidade de sua base, a saber, a materialidade discursiva" (1990, p. 179). Nessa fase, porém, Pêcheux ainda vincula o discurso (depois visto mais especificamente como "efeitos de sentido") à formação discursiva como espaço homogêneo em termos ideológicos. Isso muda substancialmente nos anos seguintes: ao discutir o papel da memória, Pêcheux, em função da opacidade dos "implícitos" constituintes da memória, e cuja regularidade pode ser quebrada por acontecimentos, aponta que a análise de discurso precisa "se distanciar das evidências da proposição, da frase [que frase?] e da estabilidade parafrástica, e a interrogar os efeitos materiais de montagens de sequências, sem buscar a princípio e antes de tudo sua significação ou suas condições implícitas de interpretação" (PÊCHEUX, 1999, p. 53-54). Por isso a ideia de "gestos de interpretação" - gestos sobre aquilo que designa, não os referentes designados. É isso o que ele diz quanto a taticamente secundarizar as "significações" (sentido, de fato).

Como se perspectiva o sujeito bakhtiniano? Certamente, nada tem a ver com os inspiradores de Pêcheux (espe- cialmente Althusser e Lacan). O projeto antissubjetivista de Pêcheux poderia traduzir sujeito como sujeito a (submetido, posição-sujeito) e não sujeito de (ativo, ego-sujeito). Então, o sujeito tem um caráter sociopsicológico, e o outro é outra pessoa, possibilidade de interação, de construção de ponte. $\mathrm{O}$ fundo é personalista e ético. Relativamente à produção de linguagem, tratam-se de locutores concretos. Isso não significa, entretanto, que se tenha um sujeito exatamente oposto àquele que aparece em $\mathrm{AD}$ (sujeito a). Sobral propõe a seguinte explicação para isso:

O elemento primordial do tratamento do sujeito pelo Círculo é a recusa de concepções transcendentais (como a de Kant, por exemplo, para o qual haveria categorias de apreensão do mundo independentes da vida concreta a que os sujeitos se submeteriam), ou psicologizantes, como as das teorias, filosóficas e outras, do sujeito cartesiano autárquico ou as vosslerianas e similares, da criatividade individual (2005, p. 106).

A percepção e o pensamento, bem como a avaliação, não ocorreriam, portanto, isoladamente da exterioridade, de situações concretas da vida, que são, necessariamente, sociais e históricas, e é desse material que isso que se chama consciência não pode ser, igualmente, um fenômeno específico do indivíduo, mas socioideologicamente caracterizado. Não há aí nenhum sujeito plenamente consciente em relação à realidade em que vive. Sua identidade é continuamente construída e modificada, e suas formas de avaliação, por isso, também sofrem deslocamento. 
Como funciona a ideologia nesse contexto? Sériot (2011) afirma que, em Voloshinov (para ele, autor de fato de MFL), a ideologia presume o mundo de produtos culturais, como uma consciência coletiva a que as pessoas se conformam, sem efeito visível do que se chamou alienação. Não há como esquecer, porém, que a ideologia oficial aparece contraposta dialeticamente, em MFL, à ideologia do cotidiano, com elementos que são recursos para a formação dos sistemas de referência na superestrutura. Ali se exerce um jogo de forças - de agregação e desagregação, sendo prevista a noção de refração em vários estágios. Se, contudo, alienação for considerada na perspectiva da totalidade dos indivíduos de uma comunidade, tal como apresentada nas obras A ideologia alemã e Grundrisse (Marx e Engels; Marx), tem-se um quadro em que não se encontra a implicação de consciência plena e ilimitada, como se julga ser evidente nos trabalhos do grupo de Bakhtin.

Sintetizo a explicação de Márkus (1974, p. 94): o fenômeno histórico da alienação leva a pensar que os produtos sociais em geral, criados em cooperação (materiais ou intelectuais), por serem comumente encontrados prontos e não havendo consciência das próprias formas históricas de cooperação, escapam ao controle dos indivíduos e parecem funcionar como uma força estranha e exterior, com suas próprias leis.

E que dizia Althusser sobre a ideologia, que repercutiu em Pêcheux? Em sua manifestação matizada sobre Marx, em A favor de Marx (ALTHUSSER, 1979, p. 204), tópico Marxismo e humanismo, de 1963, afirmava que "uma ideologia é um sistema [...] de representações (imagens, mitos, ideias ou conceitos segundo o caso) dotado de uma existência e de um papel históricos no seio de uma sociedade dada". Mais: ideologia se distingue de ciência por sua função de prática social, e é orgânica, essencial à vida social, mas predominantemente inconsciente, impondo-se estruturalmente aos homens. Nada muito divergente da explicação fornecida por Márkus.

Que representações são essas e qual sua função em relação a uma qualquer verdade? É sintomático que Althusser afaste a ideologia da ciência - o que causou um impasse a Pêcheux, que teve de admitir que "uma ciência não poderia [...] ser um ponto de vista sobre o real" ou um modelo do real; afinal, ponto de vista supõe uma posição subjetiva (PÊCHEUX, 1988, p. 179). Isso não ocorre em MFL, obra em que há referência à ciência como instituição ideológica da mesma forma que a imprensa e a literatura (cf. BAKHTIN/VOLOSHINOV, 1979, p. 106), num jogo entre ideologia do cotidiano (e seus níveis) e ideologia oficial constituída. Isso implica o movimento constante entre estabilidade e instabilidade (relação dialética), distante da ideia de "falsa consciência", no sentido de ocultamento. Miotello resume o fenômeno ideológico, na teoria, como "a expressão, a organização e a regulação das 
relações histórico-materiais dos homens" (MIOTELLO, 2005, p. 171), sem que se possa meramente opor dois espaços que configurariam uma ideologia dominante e uma ideologia dominada. Ademais, todos os materiais de linguagem "funcionam como agente e memória social", elas "se banham em todos os ambientes sociais", portanto "são tecidas por uma multidão de fios ideológicos, contraditórios entre si" (MIOTELLO, 2005, p. 172). $\mathrm{O}$ efeito de estabilidade só se consegue - e é necessário em certos níveis e esferas - por meio de organização de grupos com objetivos definidos; é nesse caso que surgem padrões a permitir a vida em caráter pragmático. Isso inclui, como se sabe, a própria grafia das palavras de uma língua nacionalizada. Bakhtin escreveu, nesse sentido: "A exatidão é necessária para a assimilação prática. O ser que se auto-revela não pode ser forçado e tolhido" (2003, p. 395).

\section{Enunciado/discurso}

Outro aspecto dessa temática diz respeito a enunciado, cujo uso aparece aqui. Em AAD-69, Pêcheux (1990a, p. 100) resolvera adotar enunciado a partir de uma distinção feita por Benveniste (1974) entre o nível semiótico e o nível semântico, cujas unidades seriam, respectivamente, o signo e a frase. A frase, no caso, teria o estatuto de fronteira entre a linguística e a teoria do discurso. Pêcheux, então, adota enunciado por sua conta para "distinguir a frase elementar enquanto objeto único sobre o qual opera o mecanismo do discurso" (1990a, p. 100). E assume que "o enunciado já é da ordem do discurso", da mesma forma que Benveniste (1974, p. 224) dizia que a frase pertence ao discurso, é língua em emprego e em ação. Isso aponta para a aproximação com a unidade fundamental da análise dialógica - enunciado. $\mathrm{E}$ o termo é comumente utilizado na área, muitas vezes podendo substituir 'discurso' nas formulações.

A par disso, Pêcheux (em parceria com Fuchs) também investiu em enunciação como vinculada à semântica, embora o eterno cuidado fosse liberar-se dos fundamentos filosóficos que tinha como idealistas, porque enunciação estaria vinculada ao acionamento da língua por um movimento subjetivo individual para a produção do enunciado (perspectiva enunciativa), e aí não se trataria de efeito-sujeito (ilusão de fonte de sentido), mas de sujeito pleno. Esse sujeito pleno, empírico e pessoal (como se indica ser aquele na $\mathrm{ADD}$, finalmente) não pode ser meramente ignorado, e isso é reconhecido periodicamente, um tanto a título de ter de lidar com ele: "Toda atividade de linguagem necessita da estabilidade destes pontos de ancoragem [situação de enunciação] para o sujeito [empírico]; se esta estabilidade falha, há um abalo na própria estrutura do sujeito e na atividade de linguagem" (PÊCHEUX; FUCHS, 1990, p. 174). Não é, porém, o que se está buscando numa teoria do discurso. Então, cabe uma torção para utilizar enunciação: "Diremos que os processos de enunciação consistem em uma série 
de determinações sucessivas pelas quais o enunciado se constitui pouco a pouco e que têm por característica colocar o 'dito' e em consequência rejeitar o "não-dito" (PÊCHEUX; FUCHS, 1990, p. 175-176).

Isso resultaria no que aparece depois como formulação, materializada no intradiscurso, resultado desse processo de "escolha" dos ditos e rejeição que vai resultar no não dito, cancelado. Não é esta uma região de inconsciência absoluta, corresponderia ao que Pêcheux chamou de esquecimento $\mathrm{n}^{\circ} 2$, que não oblitera a consciência e, por isso mesmo (como efeito que seria ideológico), traz o efeito de impressão de realidade: o tempo todo é possível retornar ao que é dito, antecipar, prever reações, especialmente considerando o interlocutor - espaço imaginário da enunciação. É quase como dizer que a característica da língua - sua sistematicidade e estruturalidade - é uma eterna dor de cabeça para a instalação de um ponto de vista discursivo. A grande diferença é que haveria sempre algo inacessível na enunciação: algo da ordem do inconsciente (esquecimento $\mathrm{n}^{\mathrm{o}} 1$ ), que seria dominante e regularia, afinal, o dizer correspondente ao esquecimento $\mathrm{n}^{\circ} 2$ - que precisaria ser obnubilado para se chegar ao objeto discursivo. Enfim, o processo todo precisa suportar o que não é discursivo, para contrastá-lo com o que seria da ordem do discursivo.

O que ocorre no contexto do dialogismo bakhtiniano, tomado como princípio geral de funcionamento dos enunciados? Antes, quero lembrar um trecho de Bakhtin (2003, p. 377-378) sobre a com- preensão de obras, com a indiscutível participação do leitor/intérprete para a consecução do processo dialógico:

Nem os sentidos do passado, isto é, nascidos no diálogo dos séculos passados, podem jamais ser estáveis (concluídos, acabados de uma vez por todas): eles sempre irão mudar (renovando-se) no processo de desenvolvimento subsequente, futuro do diálogo. [...] Questão do grande tempo (2003, p. 410, grifo do autor).

'Discurso' em Bakhtin - e não nos bakhtinianos contemporâneos - seria, começando pela designação, inexistente, na análise de Sériot (2011, p. 223), em que seria incorreta a ideia de utilizar comumente a expressão "gêneros do discurso" (outros pesquisadores usam "gêneros de texto"). Diskurs, hoje, em russo, seria a palavra utilizada apenas para traduzir discours (francês) ou discourse (inglês), mas o (efeito de) sentido seria, para os russos, mais próximo de estilo. Esta parece uma das formas de dizer que a tradução trai a opacidade dos universos intelectuais. Mas a designação já é assumida na nomeação do campo de estudos. Sem questionar propriamente esse fato, análise dialógica do enunciado poderia ser um nome adequado e teoricamente elegante.

Qual a natureza e quais as características mais fundamentais do enunciado no dialogismo? O enunciado é unidade teórica: não é uma proposição, nem uma frase. ${ }^{5}$ É unidade real da comunicação discursiva (BAKHTIN, 2003[1979], p. 269), que apresenta limites definidos pela alternância dos sujeitos (falantes); conclusibilidade (seu término); e for- 
mas estáveis de gênero. Pode-se especificar ainda (BAKHTIN, 2003[1979], p. 296-297):

a) o enunciado é um elo na cadeia da comunicação discursiva de um campo [esfera];

b) o enunciado não é indiferente a outros enunciados nem se basta a si mesmo;

c) o enunciado é pleno de ecos e ressonâncias de outros enunciados;

d) o enunciado é sempre uma resposta aos enunciados precedentes de um campo (no sentido de rejeitar, confirmar, completar, basear-se neles);

e) o enunciado comporta um elemento expressivo;

f) o enunciado é pleno de atitudes em resposta a outros enunciados.

Relembrando que, no interdiscurso, na $\mathrm{AD}$, o sentido não poderia estar constituído, sendo apenas memória, surge como relevante teoricamente a distinção feita em Bakhtin/Voloshinov (1979, $2^{\text {a }}$ parte, cap. 7, p. 114-122) entre significação e tema relativamente ao enunciado. Significação remeteria ao que é reiterável, consistindo em uma identidade e uma estabilidade reconhecidas de elementos de língua - não materialmente presentes, mas potenciais, da memória -, e tema remeteria ao que é realizado socio-historicamente pelo enunciado, único e irredutível, nesse sentido, a uma análise linguística. Ou, ainda: significação é aparato técnico para a realização do tema. Assim evitaríamos, em $\mathrm{AD}$, a formulação que prenuncia o sentido de palavras, expressões, enunciados: As palavras fazem sentido porque já tinham sentido [no interdiscurso].

\section{Gêneros de discurso/de texto}

Retomemos a questão que envolve o gênero (textual ou discursivo? Depende das perspectivas teóricas, mas não só delas). Na teoria dialógica de Bakhtin, um gênero está sempre associado a uma esfera social - um campo no interior da sociedade em que formas específicas se formam, se desenvolvem e se modificam. Elas são relativamente estáveis. $\mathrm{Em} \mathrm{AD,} \mathrm{da} \mathrm{mesma} \mathrm{forma,} \mathrm{a} \mathrm{inscrição}$ em um campo institucional é crucial, embora a caracterização interacional ou sociointeracional, típica da linha bakhtiniana, não lhe pareça suficiente ou adequada, ou seria indiferente ao que interessa analisar. Isso não impede que, ao selecionar material de análise, o analista escolha e utilize, comumente, uma designação de gênero: publicidade, propaganda, filme, reportagem, romance, poema... No tratamento, contudo, o gênero fica na sombra.

Certamente, os espaços institucionais gerenciam as formas/tipos de discurso passíveis de ocorrência em termos de gêneros, que, por outro lado, também podem constituir unidades abstratas (modelos) de construção textual, imagética, sonora, gestual, em conformidade com esses tipos, e não dispersar-se caoticamente por toda a sociedade. 
Pêcheux escreveu, ao procurar caracterizar a formação discursiva, em Semântica e discurso:

[...] aquilo que, numa formação ideológica dada, isto é, a partir de uma posição dada numa conjuntura dada, determinada pelo estado da luta de classes, determina o que pode e deve ser dito (articulado sob a forma de uma arenga, de um sermão, de um panfleto, de uma exposição, de um programa, etc.) (1988[1975], p. 160, grifo do autor).

Os gêneros, como ilustração, são apenas apontados entre parênteses, e não retornam. Portanto, não compõem uma unidade pertinente sobre a qual se deva ou se possa discutir. Enunciado ainda é a forma linguística preferida (ao lado de texto) na exposição de sequências que mereçam a consideração do analista.

Valeria a pena considerar o gênero nessa perspectiva discursiva?

Gêneros estão consubstanciados nas esferas ou campos de uso em que aparecem, com características inegáveis, embora não estabilizadas, ou melhor, existem numa escala em que se poderia dizer que há os mais estáveis e os menos estáveis, com várias configurações: os gêneros da ciência, os da religião, os da política, os da administração, os da educação, os da literatura, etc. Em Bakhtin, eles estão vinculados pelo dialogismo no processo comunicativo, considerados os inúmeros espaços de vivência em linguagem, em que ele observava exatamente $o$ fenômeno da heteroglossia - a variedade dentro de uma mesma língua e por efeito de outras ou dialetos. Não são uma tipologia vazia; aliás, Pêcheux não tinha interesse em tipologias, pelo menos no desenvolvimento de seu aparato teórico. $\mathrm{Em} \mathrm{AD}$, pouco se trabalha com tipologia. Entretanto, haveria ali um lugar para os gêneros, que poderiam fornecer um vínculo entre interdiscurso e intradiscurso, formulação, filiação e articulação nas manifestações discursivas nos campos institucionais de que são tributários, em substituição, possivelmente, à noção de formação discursiva, deslocada com o tempo até sofrer esvaziamento de sentido, pelo menos na própria teorização de Pêcheux.

Aliás, as práticas sociais desenvolvidas nos diversos campos institucionais, e também no dia a dia das trocas espontâneas, são reguladas - existe algo que entendemos como a ordem do discurso (FOUCAULT, 1971). E então o gênero funciona como um modo de estabelecer os contatos e produz um efeito de governo (dispositivo) da fala e da escrita, bem como de outras semioses. Por isso mesmo, sofre, paralelamente à pressão para se estabilizar, o processo de deslizamento, de estilização, de apagamento ou hibridismo, ajustando-se ao direcionamento das trocas - e, especialmente, aos modos específicos de fazer sentido.

Além desses argumentos, assume-se que as atitudes de resposta em reação aos enunciados "diferenciam-se acentuadamente em função da distinção entre aqueles campos da atividade humana e da vida nos quais ocorre a comunicação discursiva. [...] $\mathrm{O}$ enunciado é pleno de tonalidades dialógicas, e sem levá-las 
em conta é impossível entender até o fim o estilo de um enunciado" (BAKHTIN, 2003[1979], p. 298, grifo do autor). Ou seja, os campos institucionais, com suas características mais ou menos estabilizadas e suas próprias coerções relativamente ao funcionamento dos gêneros, comporiam esse grande espaço de criação, remodelação e deslocamento das formações genéricas.

A introdução dos gêneros na "esfera prosaica" da linguagem e sua divisão técnica em gêneros primários e gêneros secundários, explica Irene Machado (2005), são um ganho na concepção do dialogismo, mostrando a amplitude das formas culturais e seu processo de atravessamento, inclusive a própria formação dos gêneros secundários, aqueles que proliferam em sistemas formais específicos, como a ciência, a arte, a filosofia.

De outro modo, as esferas em que se distribuem os gêneros, numa sociedade, não são uma noção abstrata, mas se referem diretamente aos enunciados concretos produzidos nessas esferas (MACHADO, 2005, p. 156), e que refletem uma atitude ativa e responsiva dos participantes daquele espaço. Aliás, o momento específico de uma interação não é senão um pequeno elo na corrente do que se chama ali a comunicação discursiva e que, portanto, depende de um conjunto complexo da história e da memória que é seu entorno. Elo que, naquele momento, se fecha, produzindo enunciados; um elo é uma pequena parte, mas, em si mesmo, como enunciado, apresenta-se como algo internamente preciso e acabado.

Mas elo não é apenas texto, como em $\mathrm{AD}$ não se olha apenas sua organização interna, que existe efetivamente. É como se o próprio texto fosse um invólucro, com seu suporte próprio, que manifestasse "discursos", ou melhor, enunciados, como unidades discursivas, com sua complexidade histórica e ideológica. Afinal, gêneros se criam e se reformulam em processo, não em invenção datada. Como tais, eles apresentam, como padrão, seu próprio estilo de gênero na cultura circundante e sua efetivação sempre atualizada com, em cada momento de produção individual, sua forma expressiva/apreciativa.

Na perspectiva de Sobral: "Pode-se talvez dizer que o gênero é o continente do conteúdo que é o texto, já que o gênero incorpora textos e discursos, no âmbito das esferas de atividade, que são um componente essencial do conceito" (2008, p. 12). É uma forma, ainda, de diferenciar teoricamente gêneros de discurso e gêneros de texto, estes remetendo a formas específicas de textualização em sua expressão linguística, e aqueles à inserção global em lugares socio-históricos/ ideológicos, como propõe Sobral. E, ain$\mathrm{da}$, que textos incorporam potencialidade para a produção discursiva de sentido. As duas faces (materialidade linguística e funcionamento discursivo) interessam à análise de discurso, em sua perspectiva metodológica de oscilar entre descrição e interpretação, ao considerar as condições de produção discursiva. 
A existência cultural do gênero está vinculada à dimensão espaçotemporal (a cronotopia). Embora Bakhtin tenha dedicado este tema do grande tempo às culturas e às civilizações quanto a suas criações artísticas, podemos fazer emergir aí o material contemporâneo e tudo o que compõe sua memória e desenhar os percursos possíveis de uma existência particular. De certa forma, é como perspectivar o acontecimento (tal como aparece em Pêcheux) - histórico e discursivo - que emerge de uma corrente do passado, produz um impacto e remete ao futuro possível.

Ademais, a possibilidade de criação de vínculos entre gêneros e culturas (heteroculturalidade) é absolutamente aberta.

\section{Teorias inconciliáveis?}

Bakhtin e Pêcheux são inconciliáveis? Sim, na medida em que sejam tomados isoladamente, em seu conjunto teórico e mesmo nas incontáveis instabilidades teóricas visíveis na sequência de sua evolução teórica e de seus interesses nos momentos específicos de produção. Não, se pensarmos nas noções e em seu desenvolvimento com objetivos atualizados em campos também específicos de interesse ou novos projetos.

Essa discussão não é nova. Veja-se Guilbert Thierry (2010), ${ }^{6}$ que tematiza a herança em trabalhos contemporâneos em análise do discurso na França. Ali, justamente, há uma quase total ausência da herança de Pêcheux, e o autor admite que os estudos discursivos não poderiam limitar-se, hoje, meramente ao que Pêcheux priorizou - apesar da abertura que promoveu em seus últimos trabalhos (década de 1980). Thierry defende uma abordagem interdisciplinar que proceda, com novos instrumentos, a uma complementação a trabalhos antigos em que percepções pertinentes aparecessem. ${ }^{7}$ Então, ele defende a conciliação dos temas e conceitos de Pêcheux com epistemologias de outras abordagens discursivas, ainda que com abandono de algumas noções e reformulação de outras. Afinal, a teoria do discurso projetada por Pêcheux não foi plenamente bem-sucedida, e sabemos que o peso do materialismo histórico, uma de suas âncoras, foi amenizado num projeto que se pretendia renovado, apontando outras direções, o que ele fez ao reconhecer que a direção tomada não podia ser mantida. Sim, Pêcheux foi um pesquisador afeito a "retificações", reconhecendo seu próprio dogmatismo epistemológico (sem usar a palavra, s.m.j.) e forçando - para quem pudesse entender - a direção de seu projeto, em amplitude e abertura.

Thierry (2010) aponta Bakhtin como uma das possibilidades (outra seria a análise crítica do discurso, com Fairclough). Pêcheux havia sido radical em suas pretensões quanto ao materialismo histórico, enquanto o grupo de Bakhtin, na Rússia, manifestava suas diferenças em relação à ideologia dita oficial. Thierry aproxima Pêcheux e Bakhtin quanto ao "esquecimento" subjetivo pela interpelação ideológica, remetendo a uma 
passagem da Estética da criação verbal, capítulo sobre metodologia das ciências humanas, em que ele diz que ocorre um

[...] processo de esquecimento paulatino dos autores, depositários das palavras do outro. A palavra do outro se torna anônima, apropriam-se dela (numa forma reelaborada, é claro); a consciência se monologiza. [...] Ao monologizar-se, a consciência criadora é completada com palavras anônimas (BAKHTIN, 2003, p. 403).

Não, Bakhtin não introduz o inconsciente psicanalítico, embora ele reconheça que o "inconsciente" poderia ser um fator criativo no limiar da consciência e da palavra. Fica, no entanto, a indicação de que o processo ideológico é esquecido pelos sujeitos - embora a ideia do "isso fala”, trazida da psicanálise, seja inexistente.

Outro lado da questão que se discute é que, ao surgir na França, onde o estruturalismo predominava, Bakhtin é praticamente um estranho, "sem história”, como expressa Paveau (2010), e que começou a ser interpretado por Kristeva, Todorov e Jakobson. Estamos falando de dialogismo, e o que acontece no início dos anos 1980? O dialogismo se aclimatou rapidamente, a partir de uma entusiasmada pesquisadora: Authier-Revuz. Trabalhando com heterogeneidade(s) enunciativa(s) (AUTHIER-REVUZ, 1984), como tratou o tema, ela conseguiu articular o dialogismo com o interdiscurso (Pêcheux) e com o sujeito lacaniano, trazendo a heterogeneidade para o campo mesmo da linguística, e ela se estabeleceu muito facilmente no campo da $\mathrm{AD}$.
Por isso, vejo que a interdiscursividade se legitimou nos estudos bakhtinianos e o dialogismo (e interacionismo sub-repticiamente), no campo da $\mathrm{AD}$, porém sob a forma de heterogeneidade (que tem uma implicação epistemológica discutida por Paveau).

A ideia de interação, pressuposta em dialogismo, foi relegada por Pêcheux (1988, p. 87-94) em função da ressonância de comunicação, visto que também ocorre a não comunicação. Veja-se o tópico sobre língua e ideologia, que introduz o capítulo de Semântica e discurso, sobre a passagem da filosofia da linguagem a uma teoria materialista do discurso, o recorte em que ele admite, após considerar ser um erro de natureza sociologista (foi o termo usado), que já estaria na obra de Marx e Engels (1986), A ideologia alemã (em que, aparentemente, a língua estaria estabelecida como "meio de comunicação entre os homens") -, que sim, deve-se entender que a língua permite comunicar e também não comunicar.

Em outra perspectiva, podemos dizer, com Barthes: "A linguagem é também uma faculdade de conceitualização, de organização do mundo, é portanto muito mais que a simples comunicação. Os animais, por exemplo, comunicam-se muito bem entre si ou com o homem" (2005[1966], p. 96, grifo do autor). Ademais, a ideia de interação social pura e simples, concreta, trivial (ainda que por meio de suportes e meios variados), seria a exteriorização menos importante do processo, ao passo que o núcleo disso é a 
dialogização interna, que por isso evoca a não visibilidade do interdiscurso, com seu tecido social implícito multifacetado.

O dialogismo, afinal, é um princípio geral do discurso, com um traço inicial de utopia, talvez, como explica Paveau (2010) quando admite que teria uma função "pacificadora", uma tentativa de resguardar a socialidade da destruição de elos essenciais ao convívio. Parece claro a Emerson, no entanto, que "o princípio dialógico, tal como Bakhtin o assume, não se fia em muita coisa. O diálogo não é de forma alguma uma relação segura ou garantida" (2003, p. 278). Completei a discussão desses conflitos, em trabalho anterior, reafirmando (FURLANETTO, 2016 , p. 103) que a face mais ampla do processo está na constitutividade da relação com a alteridade, tanto de caráter intertextual como interdiscursivo e cultural, manifestando-se por rastros.

A metalinguística bakhtiniana - ou translinguística -, centrada exatamente no dialogismo, permite pensar a exterioridade (a história, a sociedade, a ideologia) nos moldes da exigência inicial de Pêcheux, ainda que a ideia de inconsciente no sentido psicanalítico, essencial no projeto de Pêcheux, nunca se tenha formulado - e, na verdade, mesmo contemporaneamente, em muitos casos fique apenas dormitando, assumido tacitamente e não experimentado analiticamente nas pesquisas. Uma translinguística - algo como uma pragmática, se apega à interação, ao processo de enunciação, já que o projeto russo salientava o caráter fundamental do social. "O enunciado enquanto totalidade não se presta a uma definição nos termos da linguística (e da semiótica). $\mathrm{O}$ termo ‘texto' não corresponde de maneira nenhuma à essência do conjunto todo do enunciado" (BAKHTIN, 2003, p. 371). O linguístico, olhado cruamente, é apenas materialidade do enunciado. Gênero, por sua vez, vincula-se a enunciado, não a texto em sua organização material. Daí que se compreenda que "gênero do discurso", para nós, seja cabível. Mas, por que não admitir: gênero do enunciado/ gêneros de enunciação?

A translinguística, enfim, em seu caráter transdisciplinar, é, na perspectiva de Sobral (2010, p. 58), a que dou apoio, uma proposta filosófica que se resume em "semiótica da cultura", como a nomina o autor, e que pode ser exposta, de modo sintético, como o espaço e o movimento cultural em que sujeitos criam e assumem sentidos para seu entorno, estabelecem um modo de viver o mundo e vão, aos poucos, transformando-o, trabalhando-o com sua avaliação social - e isso, contudo, sem homogeneização. Nesse contexto, o peso da linguagem, que carreia os sentidos e estabelece as relações, é enorme e tem necessariamente vínculo com a mobilidade de toda a cultura.

\section{Finalizando}

Não há como negar que o encapsulamento de indivíduos, grupos, sociedades e culturas, qualquer que seja o meio, 
remete, no espaço e no tempo, a um previsível empobrecimento de todos os participantes. Há, certamente, para o equilíbrio de forças e para objetivos específicos, o que se entende como preservação de identidade - individual, social, cultural -, mas, como mesmo a identidade/identificação é fugaz, há lugares-tempos para esse exercício, e outros que com a preservação convivem, convidando à abertura e ao atravessamento: na construção de conhecimentos, na educação em geral, na cultura geral, porosa para sua própria vitalização. Isso se resume em alteridade, cuja denominação não exige plural.

A conversação científica, que leva a trabalhar não só a heterogeneidade de um campo, mas também a transdisciplinaridade, e que convive na educação formal, ainda que em sua forma disciplinar (as matérias de estudo), é fonte de abertura e encontros que prometem melhor compreensão daquilo que escolhemos como campo e como objeto de reflexão, que passam a ser mais bem compreendidos no espaço-tempo de outros campos e objetos de estudo, aos quais acedemos indiretamente, mas que dizem respeito, de perto ou de longe, a nossas vidas neste mundo.

Tendo apresentado e argumentado que razões teóricas e práticas podem justificar o uso de certas categorias teóricas, metodologias, enfim, perspectivas que podem mostrar-se, inicialmente, como contraditórias, mas que, mudando-se o ângulo e a "inspiração" em outros co- nhecimentos (bem como a percepção do movimento da memória), visualizam-se aproximações produtivas, entendo que a linguística aplicada pode absorver e aproveitar, na educação científica e prática, a articulação de categorias tais como as consideradas neste trabalho, com a promoção de um estudo paralelo de teorias. Necessita-se, a par disso, da compreensão de seus fundamentos, sem o que permanece o risco de juntar peças que não se encaixam.

A linguística aplicada, apesar do nome estereotipado, não se configura hoje como uma linguística (em seu entendimento clássico) aplicada a vários campos: é uma área complexa e com delineamentos teóricos e metodológicos próprios e apropriados a seus interesses e perspectivas. É, há muito, um campo que tem feito muitas articulações promissoras, espalhando conhecimento transdisciplinar necessariamente, visto que qualquer outro campo pode ser um lugar de aplicação de suas abordagens da linguagem (em sentido amplo) sem desconhecer o funcionamento daquele campo. Tratei, pois, de estudar certas categorias teóricas, estabelecer afinidades e diferenças, para investir justificadamente nas afinidades e aproximar a compreensão de questões emergentes para seu estudo.

Deixe-se especificado que o cruzamento de limites dos campos, se poderia, eventualmente, levar à instituição de uma interface ou de outro quadro conceptual (como em psicolinguística, 
sociolinguística, linguística de corpus), não implica necessariamente esse interesse, bastando que se mantenha a coerência na articulação de aspectos das teorias, compatibilizando o uso de suas categorias e justificando o apelo feito. $\mathrm{Na}$ linguística aplicada, esse funcionamento é vantajoso, atendendo a necessidades específicas dos campos considerados, abrangendo todo o espaço de culturas.

\section{Bakhtin and/with Pêcheux? Conditions for work in applied linguistics}

\begin{abstract}
This work deals with seemingly contradictory categories, visualized in different theories - that of Bakhtin and his group (dialogical theory) and the discourse analysis of French origin -, but they deserve parallel study considering its historical encounter in Europe, due to the migration of a text written by the Russian researcher. On the one hand, it is given the assertion that it is impossible to reconcile the two theories; on the other hand, there are studies that reflect on the reasons why the two theories are used for the study of certain themes and fields by making approximations. The memory of these (dis)encounters may explain affinities and distances, and show that that theoretical resonances can be installed in those fields. This study aims to formulate arguments and provide practical reasons to the use of certain categories, simultaneously, in areas of language practice, such as applied linguistics. Thus, notions such as dis-
\end{abstract}

course, subject, ideology, memory, interdiscourse, heterogeneity and genre will be considered in this reflection.

Keywords: Discourse analysis. Dialogism. Applied linguistics.

\section{Notas}

1 Este trabalho corresponde à comunicação oral apresentada no $4^{\circ}$ Encontro Rede Sul Letras - Formação de redes em pesquisa, realizado pela Universidade do Sul de Santa Catarina Palhoça, de 11 a 13 de maio de 2016.

2 Possenti, mais especificamente, traça diferenças entre teorias de texto e teorias de discurso. Cito-o em função da ideia de conciliação ou não entre teorias. Sériot, privilegiando o contexto de produção dos escritos dos autores russos dos anos 1920-1930 e traduções, defende que não há relação entre as teses de Bakhtin e as de Pêcheux (até onde?); e que as supostas semelhanças encontradas por pesquisadores seriam mal-entendidos - um problema, diz Sériot, de desconhecimento da historicidade.

3 Pêcheux vai completar o raciocínio afirmando que o ritual de interpelação ideológica sempre vai apresentar falhas (trata-se, já, de um texto de retificação). Com esse raciocínio é que ele vai chegar à afirmação contundente de que "não há dominação sem resistência" (1988, p. 304).

4 Sobre essa questão, veja-se o artigo de Rodrigo Ielpo (2013): Da crise de uma morte aos impasses da ressurreição.

5 Frase, na perspectiva enunciativa de Benveniste, aparece como uma unidade discursiva, portanto de nível semântico (BENVENISTE, 1974, p. 224), ao passo que a unidade semiótica seria o signo, com seu valor geral e conceptual (1974, p. 219). Essas seriam as duas modalidades da função linguística: significar (o semiótico) e comunicar (o semântico).

$6 \quad$ As observações que apresento são exploradas em um trabalho publicado em coletânea sobre estudos dialógicos (FURLANETTO, 2016).

7 Exemplifico isso com o texto de Courtine (2016), Analyse du discours, années zéro: quelques réflexions rétrospectives, publicado no primeiro número da revista Policromias, de junho de 2016, sobre um trabalho antigo tratando de teoria e metodologia em $\mathrm{AD}$, também publicado na revista (com tradução). Nesse novo 
texto, um motivo crucial é a necessidade de recontextualização em função das transformações históricas da conjuntura ideológica de nascimento daquele trabalho (resultado de uma tese), no ambiente de transformação radical da estruturação do campo político interveniente (anos 1970 e início dos anos 1980). Para fazer sua arqueologia, Courtine (2016, p. 10, tradução minha) diz: "Não abordo mais hoje as coisas da mesma maneira, e não as formularia mais assim. Mas não renego nada". E, mais adiante, ele diz que, apesar de tudo, há aspectos do trabalho que: "me parecem ter conservado sua pertinência, e por vezes antecipado vias de pesquisa que em seguida iriam se abrir" (2016, p. 12, tradução minha), tal como a de memória discursiva, que depois se abriu para a questão da memória coletiva e dos lugares de memória, nas pesquisas de historiadores.

8 Assim destacado por ele, a que acrescentei uma nota no trabalho: como se fosse "algo meio recusado, meio reconhecido, meio estranho".

\section{Referências}

ALTHUSSER, Louis. A favor de Marx. Tradução de Dirceu Lindoso. 2. ed. Rio de Janeiro: Zahar, 1979.

AUTHIER-REVUZ, Jacqueline. Hétérogénéité(s) énonciative(s). Langages, Paris, n. 73, p. 98-111, 1984. Disponível em: <http:// persee.fr/web/revues/home/prescript/article/ lgge_0458-726X_1984_num_19_73_1167>. Acesso em: 24 fev. 2015.

BAKHTIN, Mikhail/VOLOSHINOV, Valentin. Marxismo e filosofia da linguagem. São Paulo: Hucitec, 1979.

BAKHTIN, Mikhail. Estética da criação verbal. Tradução de Paulo Bezerra. 4. ed. São Paulo: Martins Fontes, 2003.

BARTHES, Roland. A morte do autor. In: O rumor da língua. Tradução de Mario Laranjeira. Prefácio de Leyla Perrone-Moisés. São Paulo: Martins Fontes, 2004 [1984]. p. 57-64.

. Visualização e linguagem. In:

Inéditos - Imagem e moda. São Paulo: Martins Fontes, 2005[1966]. p. 88-97. v. 3.
BRAIT, Beth. Bakhtin e a natureza constitutivamente dialógica da linguagem. In:

(Org.). Bakhtin, dialogismo e construção do sentido. Campinas, SP: Editora Unicamp, 1997. p. 91-104.

BENVENISTE, Emile. La forme et le sens dans le langage. In: Problèmes de linguistique générale II. Paris: Editions Gallimard, 1974. p. 215-238.

COURTINE, Jean-Jacques. Analyse du discours, années zéro: quelques réflexions rétrospectives. Policromias, Rio de Janeiro, a. 1, p. 9-13, jun. 2016.

EMERSON, Caryl. Os 100 primeiros anos de Mikhail Bakhtin. Tradução de Pedro Jorgensen Jr. Rio de Janeiro: Difel, 2003.

FOUCAULT, Michel. L'ordre du discours. Leçon inaugurale ao Collège de France prononcée le 2 décembre 1970. Paris: Gallimard, 1971.

FURLANETTO, M. Marta. Texto, enunciado, ideologia - voltando no tempo pelo viés da crítica contemporânea. 2016. In: RODRIGUES, Rosângela Hammes; ACOSTA PEREIRA, Rodrigo. Estudos dialógicos da linguagem e pesquisas em linguística aplicada. São Carlos: Pedro \& João Editores, 2016. p. 67-107.

IELPO, Rodrigo. Da crise de uma morte aos impasses da ressurreição. Revista Criação \& Crítica, São Paulo, n. 11, p. 48-60, nov. 2013. Disponível em: <http://revistas.usp.br/ criacaoecritica>. Acesso em: 15 mar. 2018.

MACHADO, Irene. Gêneros discursivos. In: BRAIT, Beth (Org.). Bakhtin: conceitos-chave. São Paulo: Contexto, 2005. p. 151-166.

MAINGUENEAU, Dominique. Entrevista concedida a Fernanda Mussalim e Roberto Leiser Baronas. Linguasagem, São Carlos, n. 10, set./out. 2009. Disponível em: <http:// www.letras.ufscar.br/linguasagem/edicao10/ entrevista_maingueneau.php $>$. Acesso em: 12 jun. 2016.

MÁRKUS, György. Teoria do conhecimento no jovem Marx. Tradução de Carlos Nelson 
Coutinho e Reginaldo di Piero. Rio de Janeiro: Paz e Terra, 1974.

MARX, Karl; ENGELS, Friedrich. A ideologia alemã (I - Feuerbach). Tradução de Carlos Bruni e Marco Aurélio Nogueira. 5. ed. São Paulo: Hucitec, 1986.

MIOTELLO, Valdemir. Ideologia. In: BRAIT, Beth (Org.). Bakhtin: conceitos-chave. São Paulo: Contexto, 2005. p. 167-176.

NARZETTI, Claudiana Nair Pothin. O percurso das ideias do Círculo de Bakhtin na análise do discurso francesa. 2012. $262 \mathrm{f}$. Tese (Doutorado em Linguística e Língua Portuguesa) - Programa de Pós-graduação em Linguística e Língua Portuguesa, Faculdade de Ciências e Letras, Universidade Estadual Paulista, Araraquara, 2012.

PAVEAU, Marie-Anne. La norme dialogique. Propositions critiques en philosophie du discours. Semen, Besaçon, n. 29, p. 141-159, 2010. Disponível em: <http://semen.revues. org/8793>. Acesso em: 9 fev. 2015.

PÊCHEUX, Michel. Semântica e discurso: uma crítica à afirmação do óbvio. Tradução de Eni P. Orlandi et al. Campinas: Editora Unicamp, 1988[1975].

Papel da memória. In: ACHARD, Pierre et al. Papel da memória. Tradução e introdução de José Horta Nunes. Campinas: Pontes, 1999. p. 49-57.

Análise automática do discurso (AAD-69). In: GADET, F.; HAK, T. (Org.). Por uma análise automática do discurso. Uma introdução à obra de Michel Pêcheux. Campinas: Editora Unicamp, 1990a.

. Lecture et mémoire: Projet de recherche. In: MALDIDIER, Denise. L'inquiétude $d u$ discours. Textes de Michel Pêcheux choisis et présentés para Denise Maldidier. Paris: Editions des Cendres, 1990b. p. 285-293.

PÊCHEUX, Michel; FUCHS, Catherine. A propósito da análise automática do discurso: atualização e perspectivas (1975). In: GADET, F.; HAK, T. (Org.). Por uma análise automática do discurso. Uma introdução à obra de Michel Pêcheux. Campinas: Editora Unicamp, 1990. p. 163-252.

PLON, Michel. Analyse du discours (de Michel Pêcheux) vs analyse de l'inconscient. In: SEMINÁRIO DE ESTUDOS EM ANÁLISE DO DISCURSO - SEAD, 1, 2003. Anais... Porto Alegre: Ufrgs, 2003.

POSSENTI, Sírio. Teorias de texto e de discurso: inconciliáveis? Gragoatá, Niterói, n. 29, p. 23-34, 2010.

SÉRIOT, Patrick. Pourquoi Bakhtine n'est pas Pêcheux: un grand malentendu sur l'Analyse de Discours. In: RODRIGUES, Eduardo Alves; dos SANTOS, Gabriel Leopoldino; CASTELLO BRANCO, Luiza Katia Andrade (Org.). Análise de discurso no Brasil: pensando o impensado sempre. Uma homenagem a Eni Orlandi. Campinas: RG Editores, 2011. p. 221-230.

SOBRAL, Adail. Ético e estético: na vida, na arte e na pesquisa em ciências humanas. In: BRAIT, Beth (Org.). Bakhtin: conceitos-chave. São Paulo: Contexto, 2005. p. 103-121.

As relações entre texto, discurso e gênero: uma análise ilustrativa. Revista Intercâmbio, São Paulo, v. XVII, p. 1-14, 2008.

A estética em Bakhtin (literatura, poética e estética). In: DE PAULA, Luciane; STAFUZZA, Grenissa (Org.). Círculo de Bakhtin, teoria inclassificável. Campinas: Mercado de Letras, 2010. p. 53-88. (Série Bakhtin - Inclassificável, v. 1).

THIERRY, Guilbert. Pêcheux est-il réconciliable avec l'analyse du discours? Une approche interdisciplinaire. Semen, Besaçon, n. 29, p. 127-139, 2010. Disponível em: <http://semen.revues.org/8803>. Acesso em: 9 fev. 2015. 